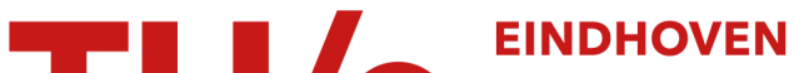

\section{Immersed boundary method applied to single phase flow past crossing cylinders - Heat transfer}

Citation for published version (APA):

Segers, Q. I. E., Kuipers, J. A. M., \& Deen, N. G. (2015). Immersed boundary method applied to single phase flow past crossing cylinders - Heat transfer. Chemical Engineering Science, 123, 322-327.

https://doi.org/10.1016/j.ces.2014.11.004

\section{Document license: \\ TAVERNE}

DOI:

10.1016/j.ces.2014.11.004

Document status and date:

Published: 01/01/2015

\section{Document Version:}

Publisher's PDF, also known as Version of Record (includes final page, issue and volume numbers)

\section{Please check the document version of this publication:}

- A submitted manuscript is the version of the article upon submission and before peer-review. There can be important differences between the submitted version and the official published version of record. People interested in the research are advised to contact the author for the final version of the publication, or visit the $\mathrm{DOI}$ to the publisher's website.

- The final author version and the galley proof are versions of the publication after peer review.

- The final published version features the final layout of the paper including the volume, issue and page numbers.

Link to publication

\section{General rights}

Copyright and moral rights for the publications made accessible in the public portal are retained by the authors and/or other copyright owners and it is a condition of accessing publications that users recognise and abide by the legal requirements associated with these rights.

- Users may download and print one copy of any publication from the public portal for the purpose of private study or research.

- You may not further distribute the material or use it for any profit-making activity or commercial gain

- You may freely distribute the URL identifying the publication in the public portal.

If the publication is distributed under the terms of Article $25 \mathrm{fa}$ of the Dutch Copyright Act, indicated by the "Taverne" license above, please follow below link for the End User Agreement:

www.tue.nl/taverne

Take down policy

If you believe that this document breaches copyright please contact us at:

openaccess@tue.nl

providing details and we will investigate your claim. 


\title{
Immersed boundary method applied to single phase flow past crossing cylinders - Heat transfer
}

\author{
Q.I.E. Segers, J.A.M. Kuipers, N.G. Deen* \\ Department of Chemical Engineering and Chemistry, Multiphase Reactors Group, Eindhoven University of Technology, PO Box 513, 5600 MB Eindhoven, \\ the Netherlands
}

\section{H I G H L I G H T S}

- Solid to fluid heat transfer is studied for crossing cylinders in the form of a wire mesh.

- Nusselt numbers obtained from the simulations were used to generate a new correlation.

\section{A R T I C L E I N F O}

\section{Article history:}

Received 17 July 2014

Received in revised form

30 October 2014

Accepted 1 November 2014

Available online 8 November 2014

Keywords:

Bubble column reactor

Crossing cylinders

Direct numerical simulation

Immersed boundary method

Heat transfer

\begin{abstract}
A B S T R A C T
In this work we study heat transfer from a complex geometry consisting of crossing cylinders subject to forced convection. For several sizes of a wire-mesh inserts direct numerical simulations (DNS) are performed using an implicit implementation of the immersed boundary method (IBM). The local heat flux is studied and compared to the total heat flux. A heat transfer correlation is derived describing the Nusselt number as a function of the Reynolds number and the ratio of the pitch to the cylinder diameter, $p / D$.
\end{abstract}

(c) 2014 Elsevier Ltd. All rights reserved.

\section{Introduction}

To intensify heat and mass transfer in bubble columns, Jain et al. (2013) suggested micro-structuring of the column internals. In bubble column reactors, fast reactions involving chemical species transferred from the gas phase to the liquid phase take place in the vicinity of the gas-liquid interface. However bubbles in this type of reactor tend to coalesce, creating larger bubbles, decreasing the specific surface area between the phases and thereby decreasing the overall contacting efficiency. Introduction of wire-meshes into the bubble column reactor is chosen as the method by which the larger bubbles are cut into smaller bubbles, thereby increasing the specific interfacial area.

To evaluate the efficiency of the wire-meshes Jain et al. (2013) developed a discrete bubble model that accounts for the cutting of bubbles by the mesh as well as the drag force exerted by the mesh on the liquid. The latter is characterized by data coming from direct numerical simulations (DNS).

\footnotetext{
* Corresponding author. Tel.: +31 402473681 .

E-mail address: N.G.Deen@tue.nl (N.G. Deen).
}

The flow past a wire-mesh has not been studied to a large extent. The hydrodynamics of the flow past cylinders has been reviewed by Gerrard (1978), Zdravkovich (1997) and Zdravkovich (2003). The hydrodynamics on crossing cylinders has been studied by Segers et al. (2013) using DNS.

An example of a study on heat and mass transfer for a cylinder array can be found in Li et al. (2005). For a comprehensive review on this subject see Goldstein et al. (2010). Wire meshes consist of intersecting cylinders, for which very little is known about the heat transfer. In this paper a more in depth research is reported on the heat transfer capabilities of intersecting cylinders, which can be used to characterize wire-meshes.

To determine the heat transfer we use DNS, where all the details of the flow are resolved. The results obtained from this paper are directly applicable in larger scale simulations where the flow around objects would not be fully resolved. In that case, objects are implemented as point sources with appropriate closure equations for the momentum and heat transfer obtained from DNS.

This work is organized as follows: first a short introduction on the immersed boundary method is given. Next, the choice of the simulation domain is evaluated, continued by a discussion of the results. The local heat transfer of the wire-mesh section is 
elaborated upon, followed by the overall heat transfer. From the obtained results a correlation for the overall heat transfer is derived depending on the wire-mesh and flow parameters.

\section{Immersed boundary method and simulation}

A short introduction on the immersed boundary method (IBM) is given in this section. For a more complete description the reader is referred to Deen et al. (2012).

The transport phenomena of a fluid with constant transport properties are governed by the conservation equations of mass, momentum and thermal energy, given by the following equations:

$\nabla \cdot \mathbf{u}=0$

$\rho \frac{\partial}{\partial t} \mathbf{u}+\rho \nabla \cdot \mathbf{u} \mathbf{u}=-\nabla P-\nabla \cdot \boldsymbol{\tau}+\rho \mathbf{g}$

$\rho c_{p}\left(\frac{\partial T}{\partial t}+\nabla \cdot \mathbf{u} T\right)=k \nabla^{2} T$

where $\rho$ is the fluid density, $T$ is the fluid temperature, $\mathbf{u}$ is the velocity, $P$ is the pressure, $c_{p}$ is the heat capacity, $k$ is the thermal conductivity and the stress tensor $\boldsymbol{\tau}$ is given by

$\boldsymbol{\tau}=-\mu\left(\nabla \mathbf{u}+(\nabla \mathbf{u})^{\top}\right)$

The convective terms are discretized by means of an AdamsBashforth scheme and the diffusive terms are discretized by means of a Crank-Nicolson scheme. The immersed boundaries (i.e. the wires) are accounted for in an implicit manner, by eliminating the influence of grid nodes that coincide with the solid object. The velocities and temperature are prescribed at the surface of the immersed object by expressing them in terms of the neighboring nodes through applying a quadratic fit. Deen et al. (2012) have shown that results obtained with this method agree with the theoretical results of Zick and Homsy (1982) for flow past periodic static arrays of spheres and yield second-order accurate results.

For simulation time speed-up, an adaptive time-stepping procedure has been applied. The procedure is based on the Courant number or $C_{C F L}$ number. Following work published by Hundsdorfer et al. (2003) the correct value for $C_{C F L}$ for implicit second-order methods should be $\frac{2}{3}$. The grid-size is fixed in our simulations. Thus the only parameter to be changed is the timestep $\Delta t$. Every time-step $C_{C F L}$ is calculated and depending on whether this value is higher or lower than $\frac{2}{3}$ the time-step is adjusted accordingly. When a time-step has been calculated where the aforementioned condition is not met, the time-step is decreased and the time-step is redone to avoid unstable simulations.

In order to characterize the heat transfer a unit cell of the wire mesh was considered (see Fig. 1), with free-slip vertical walls, uniform fluid inflow and a pressure boundary at the top. The domain width and the depth are equal to the pitch $p$ between the wires. The diameter $D$ is varied from $1 / 8$ to $1 / 2$ the domain width. The non-dimensional $p / D$-ratio is hereby introduced. The object is kept at a constant uniform temperature, i.e. we assume that the heat transfer in the interior of the solid object is infinitely fast. As a result the resistance for heat transfer lies in the fluid and is characterized by the thermal conductivity of the fluid and the heat flux from the object to the fluid, $Q_{s \rightarrow f}$ is calculated by taking the surface integral over the objects

$Q_{S \rightarrow f}=-\iint_{S}(k \nabla T \cdot \mathbf{n}) d S$

A small adaptation of the pressure boundary needs to be done to account for the eddies created at the immersed boundary reaching the outflow boundary. As these eddies reach the upper boundary, the standard pressure boundary is unable to cope with the velocities tangential to the boundary. Singularities occur and the simulations eventually diverge.

The outflow boundary condition is stabilized by adding a buffer zone. The flow in the buffer zone is stabilized and does not influence the area of interest, being in this case the immersed boundary at the upstream position. Stabilization is achieved by gradually increasing the viscosity in the buffer zone using the following equation:

$\frac{\mu}{\mu_{0}}=10\left(\frac{z-H_{0}}{h-H_{0}}\right)^{2} \quad z \leq H_{0}$

with $H_{0}$ being the start of the buffer layer and $h$ being the height of the simulation domain.
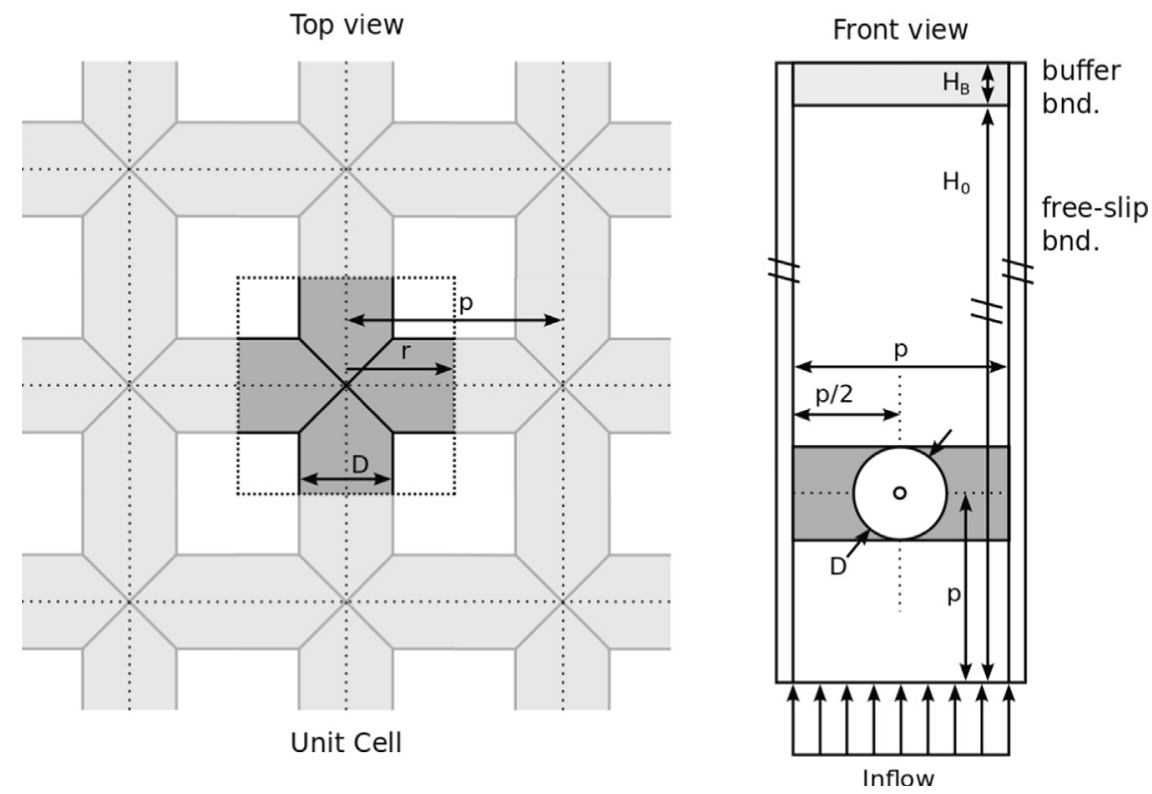

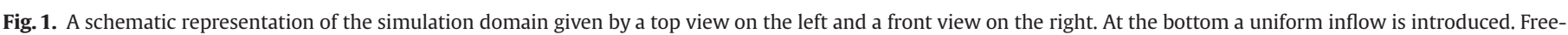

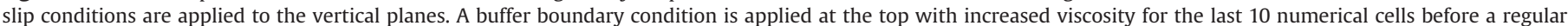
pressure boundary is applied. 
A similar approach can be found in the literature, a good review on implementation of the boundary conditions was reported by Turkel (1983).

For the convective heat transfer the Reynolds number and the Prandtl number are the important dimensionless groups. The Reynolds number is set by defining the inflow velocity and the diameter of the cylinders used in the wire-mesh section

$\operatorname{Re}=\frac{\rho U_{\infty} D}{\mu}$

All simulations were conducted at a constant Prandtl number, which is given by

$\operatorname{Pr}=\frac{\nu}{\alpha}=\frac{c_{p} \mu}{k}$

where $\nu$ is the kinematic viscosity, $\alpha$ the thermal diffusivity, $\mu$ the dynamic viscosity, $k$ the thermal conductivity and $c_{p}$ the specific heat. The Prandtl number is kept at unity for all simulations done. Preliminary simulations showed that flow structures in the wake of the object can travel upstream, thereby influencing the wall to fluid heat transfer. To ensure that the simulation results are independent of the domain size downstream of the object we tested different configurations.

At $p / D=2$, the vortices created behind the wire-mesh turn out to be strongest for the simulations done. In that case, the flow is restricted more and higher fluid velocities occur due to the smaller fraction of open area. The smaller fraction of open area also causes the flow around the object to become more dynamic at higher Reynolds numbers and thus the calculated Nusselt value oscillates. To compare the results for the different domain parameters a boxwhisker plot was prepared using the heat transfer values during 6000-8000 time-steps of the simulation, see Fig. 2. A steady-state was reached after about $5 \mathrm{~s}$.

Simulations are done with the parameters given in Table 1. Domains with several lengths were used as shown in Table 2. The median of the heat transfer coefficient, average heat transfer coefficient $(\bar{Q})$ and the standard deviation of the heat transfer coefficient $(\sigma)$ are also given in Table 2 .

Results for $p / D=2$ and $\operatorname{Re}=400$ and several domain lengths are given in Fig. 2. The results show that, even without an increase of the number of cells at the downstream portion of the domain, simulations using $N x \times N y \times N z=40 \times 40 \times 110$ with increasing

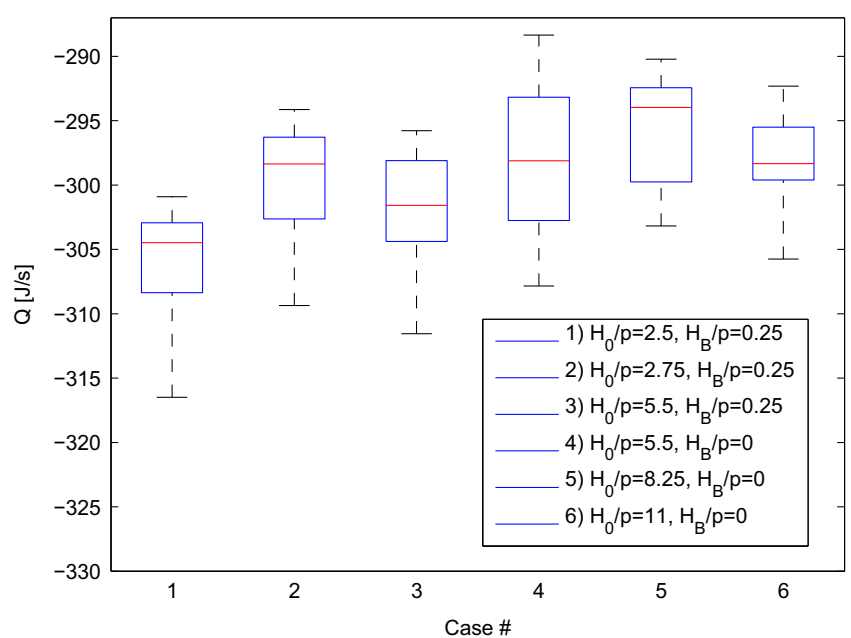

Fig. 2. Box whisker plots of the amount of heat transfer at the wire-mesh element. Simulation parameters given in Table 2 . The red lines indicate the median values. The boxes indicate the second and the third quartile of the data set. The error bars indicate the first and the last quartile of the data set. (For interpretation of the references to color in this figure caption, the reader is referred to the web version of this paper.)
Table 1

Physical parameters for simulation for determining domain size.

\begin{tabular}{ll}
\hline Parameter & Value \\
\hline$p$ & $0.08 \mathrm{~m}$ \\
$D$ & $0.04 \mathrm{~m}$ \\
$p / D$ & 2 \\
$U_{0}$ & $0.5 \mathrm{~m} / \mathrm{s}$ \\
$\mu$ & $0.05 \mathrm{~N} \mathrm{~s} / \mathrm{m}^{2}$ \\
$\rho$ & $1000 \mathrm{~kg} / \mathrm{m}^{3}$ \\
$c_{p}$ & $10 \mathrm{~J} /(\mathrm{kg} \mathrm{K})$ \\
$\Delta x$ & $0.002 \mathrm{~m}$ \\
$\Delta t$ & $\approx 4.0 \times 10^{-4} \mathrm{~s}$ \\
$\Delta T$ & $100 \mathrm{~K}$ \\
\hline
\end{tabular}

Table 2

Simulation parameters for determining domain size, both with and without buffer boundary conditions. The corresponding results are shown in Fig. 2.

\begin{tabular}{llllll}
\hline Case \# & $H_{0} / p$ & $H_{B} / p$ & Median & $\bar{Q}$ & $\sigma$ \\
\hline 1 & 2.5 & 0.25 & -304.5 & -306.0 & 4.24 \\
2 & 2.75 & 0.25 & -298.4 & -299.6 & 4.27 \\
3 & 5.5 & 0.25 & -301.6 & -302.1 & 4.20 \\
4 & 5.5 & 0 & -298.1 & -297.7 & 5.95 \\
5 & 8.25 & 0 & -294.0 & -296.0 & 4.19 \\
6 & 11 & 0 & -298.3 & -298.8 & 4.35 \\
\hline
\end{tabular}

viscosity remain stable and produce results which are similar in magnitude to results obtained from simulations for which the domain was quadrupled in length. Note that a similar simulation done with the same domain length but with constant viscosity diverges (not shown). It can be observed that the use of the buffer layer has no significant effect on the main characteristics of the heat transfer. Moreover, simulations done without the buffer layer would either crash or require prohibitively long domains. Therefore, we used a buffer layer and a domain length of $H_{0} / p=5.5$ for the remaining results in this work.

\section{Heat transfer single cylinder and a wire mesh}

The heat transfer for an object in a flow is characterized by the Nusselt number, which is given by

$\mathrm{Nu}=\frac{h D}{k}$

where the heat transfer coefficient $h$ is calculated from the heat flux at the wall, $Q$, the designated surface area $A$ and $\Delta T$ is the temperature difference between the inlet temperature and the surface temperature

$h=\frac{Q}{A \Delta T}$

To evaluate the local, azimuthally averaged, Nusselt number, a surface integral is taken of the wire-mesh to calculate the local surface area. The local surface area is used in the Nusselt equation together with the local azimuthally averaged heat flux to calculate the local Nusselt number

$\mathrm{Nu}_{l o c}=\frac{Q_{l o c} D}{A_{l o c} k \Delta T}$

For a single cylinder the total heat flux $Q$ is used, together with the total surface area of the cylinder $A=\pi D p$. When this is 
substituted in Eq. (9) we obtain

$\mathrm{Nu}_{1 \mathrm{cyl}}=\frac{Q}{\pi p \Delta T k}$

for the Nusselt number of a single cylinder. For the case where two crossing cylinders are simulated the surface area is equal to that of two cylinders minus the area inside the intersection of the two cylinders (see Fig. 3). This shape is also known as a bicylinder or the Steinmetz solid (Hogendijk (2002)). The surface area of the intersection is $4 D^{2}$. So, the surface area of the intersecting cylinders becomes $A=2 \pi D p-4 D^{2}$, and the Nusselt number

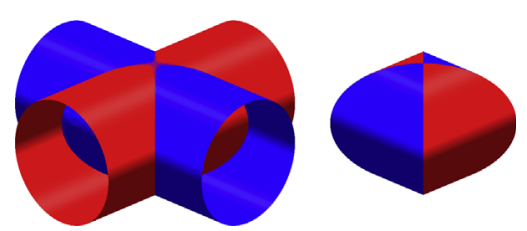

Fig. 3. Intersecting cylinders on the left with the bicylinder shown on the right. The surface area of the right object is equal to $4 D^{2}$.

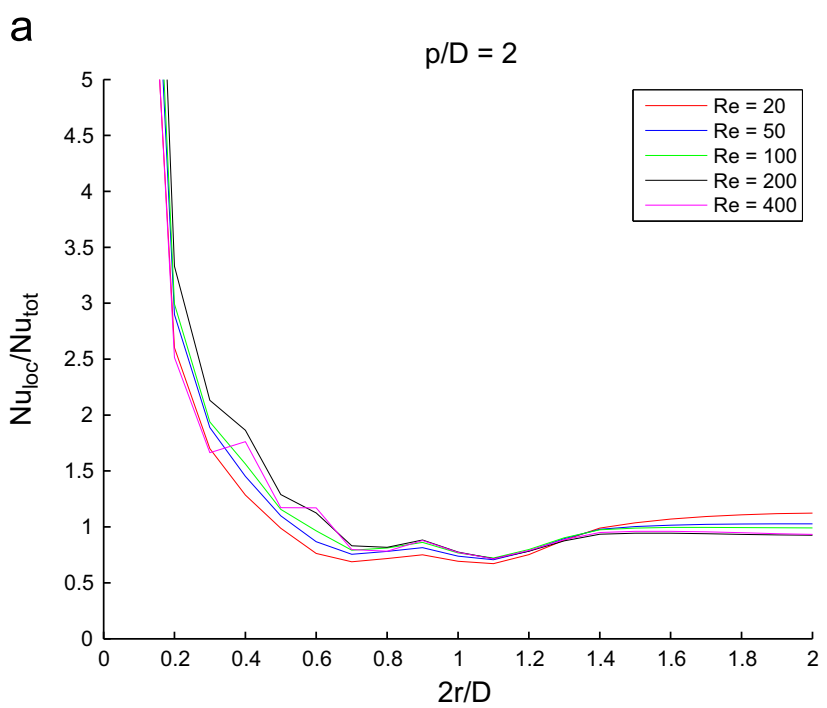

C

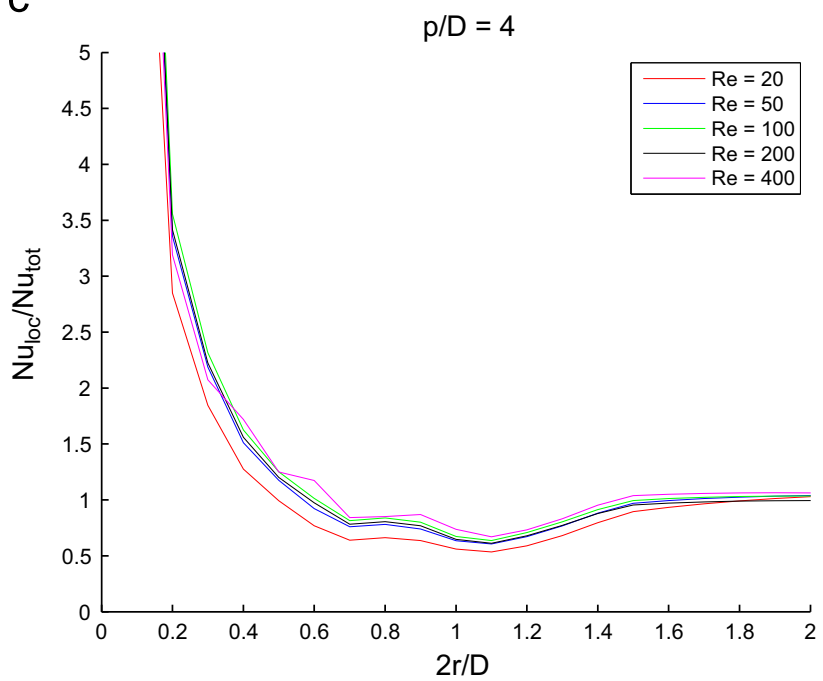

becomes

$\mathrm{Nu}_{2 \text { cyls }}=\frac{Q}{2(\pi p-4 D) \Delta T k}$

\section{Results}

To characterize the heat transfer of a wire mesh insert under practically relevant conditions, simulations were performed for Reynolds numbers ranging from 20 to 400 and pitch to diameter

Table 3

Nusselt numbers from simulation results.

\begin{tabular}{rrrrr}
\hline Re & $\begin{array}{r}p / D=2 \\
\varepsilon=0.25\end{array}$ & $\begin{array}{c}p / D=3 \\
\varepsilon=0.44\end{array}$ & $\begin{array}{r}p / D=4 \\
\varepsilon=0.56\end{array}$ & $\begin{array}{r}p / D=8 \\
\varepsilon=0.77\end{array}$ \\
\hline 20 & 3.96 & 3.42 & 3.21 & 2.95 \\
50 & 6.70 & 5.57 & 5.11 & 4.54 \\
100 & 9.65 & 7.94 & 7.21 & 6.37 \\
200 & 13.99 & 11.02 & 10.17 & 9.07 \\
400 & 17.78 & 15.01 & 13.98 & 12.59 \\
\hline
\end{tabular}

b

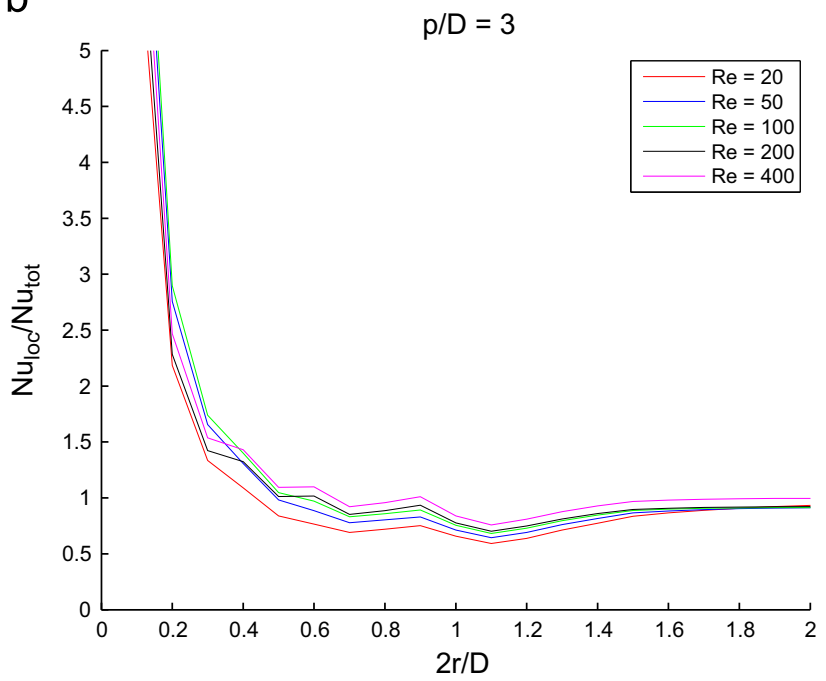

d

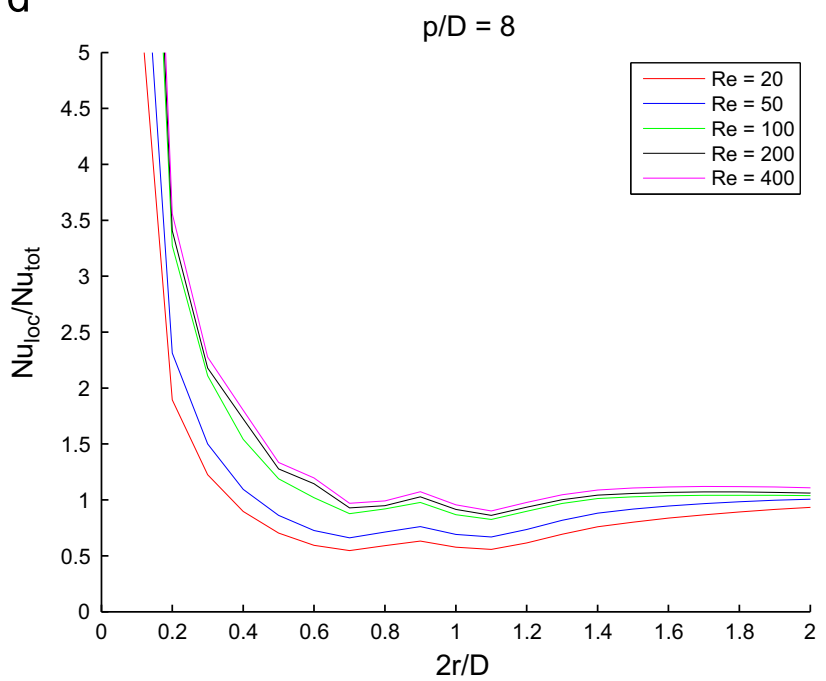

Fig. 4. Local Nusselt number divided by total Nusselt number against the distance from the cylinder intersection, $r$, divided by the radius, $D / 2$, for Reynolds numbers 20,50 , 100,200 and 400 for value of $p / D$. (a) $p / D=2$. (b) $p / D=3$. (c) $p / D=4$. (d) $p / D=8$. 
ratios $(p / D)$ ranging from 2 to 4 . In this section we will discuss the simulation results. First the local Nusselt number is examined and then the total Nusselt number of the entire wire mesh insert. The latter is used for the development of a general Nusselt correlation for flow past wire mesh inserts.

\subsection{Local Nusselt number}

The local Nusselt number is calculated here to show the evolution of the heat transfer along the cylinder walls and especially in the area where the cylinders cross.

The local Nusselt number is normalized by the total Nusselt number of the two crossing cylinders. Note that, for the ease of interpretation, all four ends of the wire-mesh in the unit cell have been summed, which is allowed as the heat transfer for the four parts of the wire-mesh unit cell are symmetrical. For this reason $r$ is defined as the distance from the point where the two cylinders cross and is directed along the cylinder axis (see Fig. 1). From $2 r / D>1$ the cylinders no longer overlap.

The computed local Nusselt numbers are shown in Fig. 4. A very large local Nusselt number is observed at the wire-mesh center. Here the local Nusselt number becomes much higher than the total Nusselt number. This is mainly caused by the relative decrease in the local area which is used for the calculation of the local Nusselt number. For the cylindrical part of the object, the complete circumference is responsible for the heat transfer. Nearing the cylinder intersection the surface area decreases, as illustrated in Fig. 3.

\subsection{Total Nusselt number}

The obtained total Nusselt numbers for the entire object are given in Table 3 for all Reynolds numbers and $p / D$ values. These results are also shown in Fig. 5. The obtained simulation data were fitted, to find a relationship between the Nusselt number, the Reynolds number and the (minimum) open area fraction, $\varepsilon=(1-D / p)^{2}$. As can be seen in Fig. 6 , the simulation data are well described by the following equation:

$\mathrm{Nu}=0.60 \mathrm{Re}^{1 / 2} \varepsilon^{-1 / 3}$

We would expect that like in many other forced convection heat transfer problems, Nu also scales with $\operatorname{Pr}^{1 / 3}$, although this has not been investigated in this work.

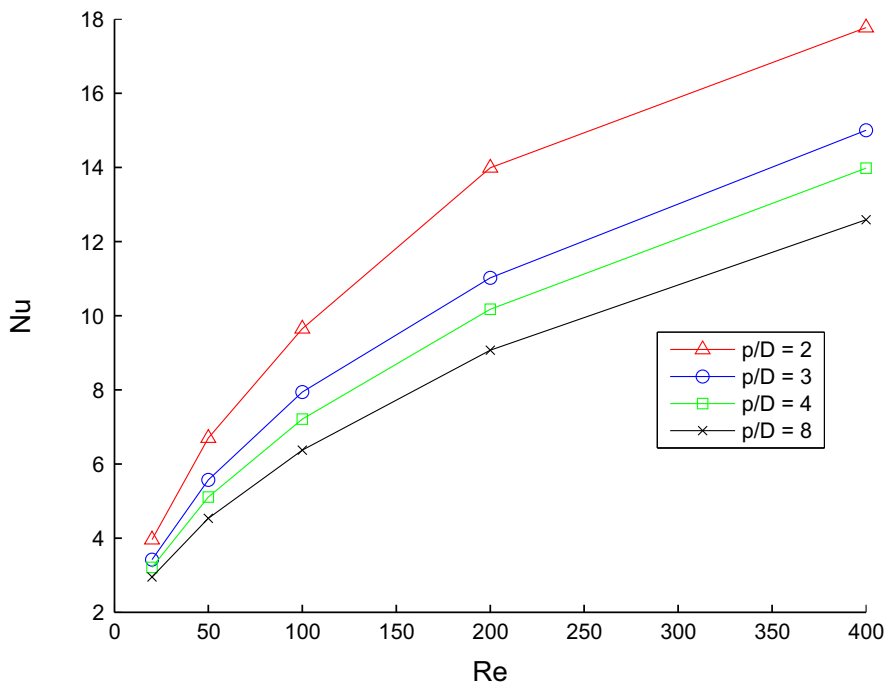

Fig. 5. Nusselt number for Reynolds numbers $20,50,100,200$ and 400 for $p / D=2$, 3,4 and 8 .

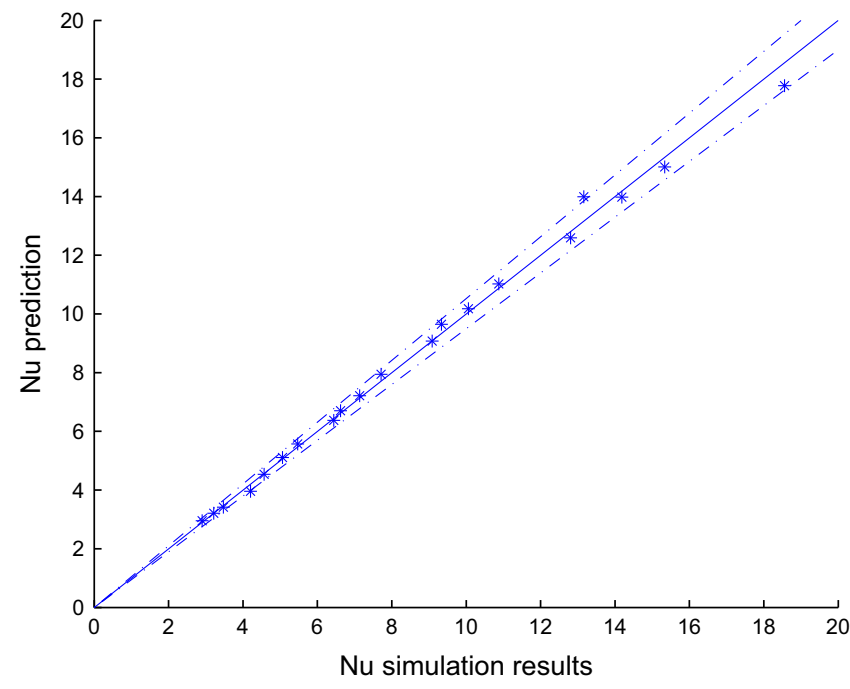

Fig. 6. Parity plot for the fitted Nusselt results $\mathrm{Nu}=0.6 \mathrm{Re}^{1 / 2} \varepsilon^{-1 / 3}$ for Reynolds numbers $20,50,100,200$ and 400 for $p / D=2,3,4$ and 8 . Confidence intervals of $\pm 5 \%$ are indicated by the dash-dotted lines.

The total Nusselt number results show a clear dependency on the $p / D$-ratio and the Reynolds number. The decreased $p / D$-ratio clearly causes a larger flow contraction (decreased open area fraction), therefore increasing the relative velocity and increasing the heat transfer. Higher Reynolds numbers cause the heat transfer to increase even further.

As we have seen earlier, results for all $p / D$-ratios give similar values for $\mathrm{Nu}_{l o c}$ in the vicinity of the intersection, provided that they are normalized by $\mathrm{Nu}_{t o t}$. That is, the dependency of the Reynolds number and $p / D$ is mostly captured by the total Nusselt number.

\section{Conclusions}

The DNS method by Deen et al. (2012) using an implicit implementation of the immersed boundary method has been applied to study flow past crossing cylinders. The heat transport from the immersed object to the fluid has been studied by computing the local heat transfer coefficient and the total heat transfer coefficient of the wire-mesh insert, for different Reynolds numbers and pitch/diameter ratios. The normalized heat transfer does not depend on the Reynolds number or the pitch/diameter ratio. The total (non normalized) flux was shown to be dependent on the Reynolds number and the pitch/diameter ratio though. A correlation for the total heat transfer with respect to the $p / D$-ratio and the Reynolds number was obtained and given in Eq. (14).

\section{Nomenclature}

$\begin{array}{ll}\text { Roman letters } & \\ C_{D} & \text { drag coefficient }(-) \\ c_{p} & \text { specific heat }(\mathrm{J} / \mathrm{kg} \cdot \mathrm{K}) \\ D & \text { diameter }(\mathrm{m}) \\ F & \text { force }(\mathrm{N}) \\ \mathbf{g} & \text { gravity }\left(\mathrm{m} / \mathrm{s}^{2}\right) \\ H & \text { height }(\mathrm{m}) \\ k & \text { thermal conductivity }\left(\mathrm{W} / \mathrm{K} \mathrm{m}^{2}\right) \\ L & \text { length }(\mathrm{m}) \\ N & \text { number }(-) \\ P & \text { pressure }(\text { bar }) \\ p & \text { pitch }(\mathrm{m})\end{array}$




\section{Greek letters}

$\varepsilon$

$\mu$

$\rho$

$\sigma$

\section{Subscripts}

0

B

CFL

$\infty$

l

loc

$\max$

$\min$

$s$

tot heat transfer $(\mathrm{J} / \mathrm{s})$

average heat transfer $(\mathrm{J} / \mathrm{s})$

normalized axial position (-)

Reynolds number (-)

time (s)

velocity $(\mathrm{m} / \mathrm{s})$

fluid velocity $(\mathrm{m} / \mathrm{s})$

spatial coordinate (-)

spatial coordinate (-)

spatial coordinate $(-)$

area fraction (-)

dynamic viscosity (Pa s)

density $(\mathrm{kg} / \mathrm{m})$

standard deviation (-)

stress tensor $(\mathrm{Pa})$

initial

boundary

drag

Courant-Friedrichs-Lewy condition

at infinity

liquid

local

maximum

minimum

solid

total

\section{Acknowledgements}

The authors would like to thank the European Research Council for its financial support, under its Starting Investigator Grant scheme, Contract number 259521 (CuttingBubbles).

\section{References}

Deen, N.G., Kriebitzsch, S., van der Hoef, M.A., Kuipers, J., 2012. Direct numerical simulation of flow and heat transfer in dense fluid-particle systems. Chem. Eng. Sci. 81.

Gerrard, J., 1978. The wakes of cylindrical bluff bodies at low Reynolds number. Philos. Trans. R. Soc. Lond. A 288.

Goldstein, R., Ibele, W., Patankar, S., Simon, T., Kuehn, T., Strykowski, P., Tamma, K., Heberlein, J., Davidson, J., Bischof, J., Kulacki, F., Kortshagen, U., Garrick, S. Srinivasan, V., Ghosh, K., Mittal, R., 2010. Heat transfer-a review of 2005 literature. Int. J. Heat Mass Transf. 53.

Hogendijk, J.P., 2002. The surface area of the bicylinder and Archimedes' method. Historia Math. 29.

Hundsdorfer, W., Ruuth, S.J., Spiteri, R.J., 2003. Monotonicity-preserving linear multistep methods. Soc. Ind. Appl. Math. 41.

Jain, D., Lau, Y., Kuipers, J., Deen, N., 2013. Discrete bubble modeling for a microstructured bubble column. Chem. Eng. Sci. 100.

Li, T., Kuipers, J., Deen, N., 2005. Numerical investigation of hydrodynamics and mass transfer for in-line fiber arrays in laminar cross-flow at low Reynolds numbers. Chem. Eng. Sci. 60.

Segers, Q.I., Kuipers, J., Deen, N., 2013. Immersed boundary method applied to single phase flow past crossing cylinders. Chem. Eng. Sci. 100.

Turkel, E., 1983. Progress in computational physics. Comput. Fluids 11.

Zdravkovich, M., 1997. Flow Around Circular Cylinders. Volume 1: Fundamentals. Oxford University Press, Oxford.

Zdravkovich, M., 2003. Flow Around Circular Cylinders. Volume 2: Applications. Oxford University Press, Oxford.

Zick, A., Homsy, G., 1982. Stokes flow through periodic arrays of spheres. J. Fluid Mech. 115. 